Check for updates

Cite this: RSC Adv., 2021, 11, 31373

Received 1st September 2021

Accepted 14th September 2021

DOI: 10.1039/d1ra06589k

rsc.li/rsc-advances

\section{An efficient synthesis of RNA containing GS- 441524: the nucleoside precursor of remdesivir}

\author{
Ramkumar Moorthy, Samantha A. Kennelly, (D) Deborah J. Rodriguez \\ and Daniel A. Harki (D)*
}

Remdesivir is an antiviral nucleoside phosphoramidate with activity against multiple viruses, including SARSCoV-2. To enable studies of viral polymerases with RNA containing remdesivir, we report an efficient synthesis of a phosphoramidite of GS-441524, the nucleoside precursor of remdesivir, and its incorporation into RNA using automated solid-phase RNA synthesis.
Remdesivir is a $1^{\prime}$-cyano-substituted, 4-aza-7,9-dideazaadenosine phosphoramidate prodrug that displays broad-spectrum antiviral activity against viruses such as hepatitis C (HCV), yellow fever (YFV), dengue-2 (DENV-2), influenza A, parainfluenza 3, Ebola virus (EBOV) and SARS-CoV (Fig. 1). ${ }^{1}$ Currently, remdesivir is the only nucleoside drug approved by the US Food and Drug Administration to combat COVID-19. ${ }^{2}$ Remdesivir is metabolized intracellularly to its $5^{\prime}$-monophosphate and then further biotransformed to its active metabolite, the $5^{\prime}$-triphosphate. ${ }^{3}$ Viral RNA-dependent RNA polymerases (RdRp) mis-incorporate the resulting nucleotide, which stalls RNA synthesis resulting in antiviral effects. ${ }^{4}$ This promising antiviral activity has prompted
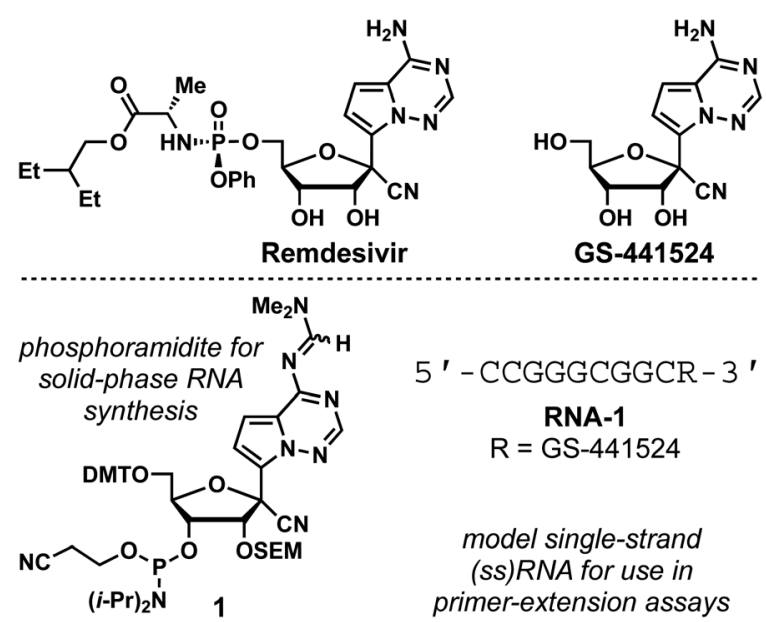

GS-441524

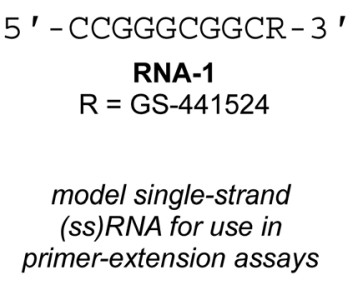

Fig. 1 Structures of remdesivir, GS-441524, phosphoramidite 1, and RNA-1.

Department of Medicinal Chemistry, University of Minnesota, $22316^{\text {th }}$ Street S.E., Minneapolis, MN, 55455, USA. E-mail: daharki@umn.edu

$\dagger$ Electronic supplementary information (ESI) available: Experimental details for the synthesis of nucleosides and RNA; NMR spectra. See DOI: 10.1039/d1ra06589k studies of viral polymerases with RNA-incorporated drug, necessitating methods to synthesize RNA containing the nucleoside precursor of remdesivir, GS-441524 (Fig. 1). Recently, a GS-441524 phosphoramidite synthesis was reported and that compound was subsequently used in solid-phase RNA synthesis to enable mechanistic studies of SARS-CoV-2 RdRp stalling. ${ }^{5}$ Here, we report a concise and high-yielding synthesis of an alternative GS-441524containing phosphoramidite, 1 , which is prepared in $14 \%$ overall yield in 6 steps from GS-441524.

We initiated the synthesis of phosphoramidite $\mathbf{1}$ by attempting to protect the primary exocyclic amine of GS-441524 with a benzoyl group using the Jones transient $N$-benzoylation method (trimethylsilyl chloride, benzoyl chloride, pyridine and $\mathrm{NH}_{4} \mathrm{OH}$ ), which resulted in decomposed product. ${ }^{6}$ Therefore, we altered the order of protecting group installation. The $3^{\prime}$ - and $5^{\prime}$-alcohols were protected using di(tert-butyl)chlorosilane ${ }^{7}$ to yield 2 in $86 \%$ yield (Scheme 1). Of note, this protecting group can be selectively removed under mild acidic conditions $s^{8,9}$ without affecting other fluoride-labile groups present at the $2^{\prime}$ $\mathrm{OH}$ (e.g., SEM, TBS, or TOM). We next turned our attention to protecting the exocyclic amine with dimethyl-formamidine due to constrains imposed by the free $2^{\prime}-\mathrm{OH}$ in using other protecting groups. Protection of the amine of 2 was optimized by reacting 2 with $N, N$-dimethylformamide dimethyl acetal under various reaction conditions (Table 1).

Initially, the reaction was performed in DMF at room temperature for 48 hours yielding imine diastereomers 3a and

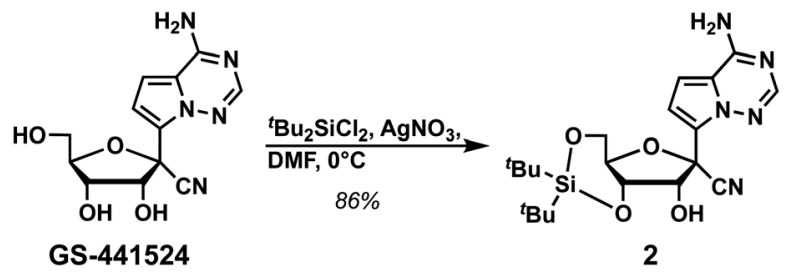

Scheme 1 Synthesis of compound 2. 
Table 1 Optimization of exocyclic amine 2 protection using N,Ndimethylformamide dimethyl acetal ${ }^{a}$

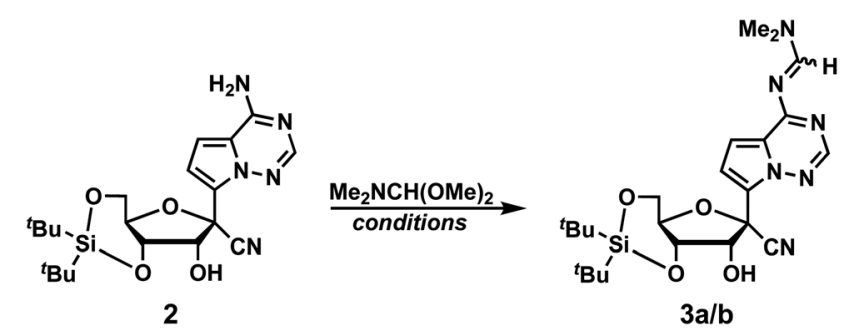

\begin{tabular}{lllll}
\hline Entry & Temp $\left({ }^{\circ} \mathrm{C}\right)$ & Time $(\mathrm{h})$ & Solvent & Yield $^{e}(\%)$ \\
\hline 1 & RT & 48 & DMF & 66 \\
2 & 65 & 24 & DMF & 58 \\
$3^{b}$ & 65 & 24 & DMF & 57 \\
$4^{c}$ & 65 & 24 & DMF & 55 \\
$5^{d}$ & 65 & 1 & DMF & 59 \\
6 & 65 & 24 & DMA & 52 \\
7 & 65 & 24 & Pyridine & 57 \\
$8^{f}$ & 65 & 24 & - & 71
\end{tabular}

${ }^{a}$ Unless otherwise stated, the reactions were performed on a $0.10 \mathrm{mmol}$ scale using 2 (1.0 equiv.) and $N, N$-dimethylformamide dimethyl acetal (4.0 equiv.) in the corresponding solvent $(1.0 \mathrm{~mL}$ organic solvent). ${ }^{b}$ Reaction performed with MS $4 \AA(50 \mathrm{mg}) .{ }^{c}$ Reaction performed with $\mathrm{MgSO}_{4}(50 \mathrm{mg}) .{ }^{d}$ Reaction was performed in a microwave synthesizer at $200 \mathrm{~W}, 17$ PSI. ${ }^{e}$ Yield represents a mixture of diastereomers (for entries 1-7 the reaction resulted in 3a as the major diastereomer and $\mathbf{3 b}$ as the minor diastereomer). ${ }^{f}$ Reaction yielded $\mathbf{3 b}$ as the only diastereomer. DMF: $N, N$-dimethyl formamide; DMA: $N, N$-dimethyl formamide acetal. Reactions were performed in duplicate and yields shown are an average. Note: $\mathbf{3 a}$ and $\mathbf{3 b}$ are separable diastereomers; stereochemical assignments of the imines of $\mathbf{3 a}$ and $\mathbf{3 b}$ were not conducted since both protecting groups are ultimately cleaved.

3b in $66 \%$ yield. The $E / Z$ stereochemical identities of $\mathbf{3 a}$ and $\mathbf{3 b}$ were not determined due to a lack of diagnostic NMR resonances and the inconsequential nature of the olefin geometry: the imine protecting groups are ultimately cleaved. Of note, diastereomer 3a has the higher chromatographic $\mathrm{R}_{\mathrm{f}}$ compared to $\mathbf{3 b}$. To improve reaction efficiency, the solution was heated at $65{ }^{\circ} \mathrm{C}$ for 24 hours, which resulted in a similar yield of product formation $(58 \%)$. For imine condensation, removal of water drives the reaction towards product formation, therefore the reaction was performed with additives such as $4 \AA$ molecular sieves and $\mathrm{MgSO}_{4}$ at $65{ }^{\circ} \mathrm{C}$. However, neither condition improved the reaction yield (entries 3 and 4, Table 1 ). We next investigated microwave conditions (200 W, 17 PSI) with heating to $65{ }^{\circ} \mathrm{C}$ for 1 hour, which resulted in similar yields to reactions performed at room temperature or at $65{ }^{\circ} \mathrm{C}$ (entry 5, Table 1). Switching solvent to DMA or pyridine resulted in a lower or similar yield compared to DMF (entries 6, and 7, Table 1). Interestingly, solvent-free conditions resulted in a slight improvement of product formation compared to reactions performed with solvent (entry 8, Table 1). However, the neat condition did not result in the full conversion, and we were unable to purify product from the starting material. Since these studies resulted in no significant improvement in yield, we used conditions from entry 1 (Table 1 ) with pure diastereomer $\mathbf{3 a}$ to continue the synthesis of phosphoramidite 1 .

We next investigated conditions to protect the $2^{\prime}$-alcohol of 3a. Although a variety of $2^{\prime}$-alcohol protecting groups have been successfully utilized in phosphoramidite synthesis, including base-labile, ${ }^{10}$ acid-labile, ${ }^{11}$ fluoride-labile, ${ }^{12}$ reductively removable, ${ }^{13}$ and photo-labile groups, ${ }^{14}$ we elected to utilize a fluoridelabile protecting group and initially investigated the $2^{\prime}$-OTBS group. However, to our surprise, we found that the typical reaction conditions to install TBS groups (e.g., TBSCl, imidazole, DMAP and DMF at room temperature for 48 hours) resulted in no reaction. Addition of $\mathrm{AgNO}_{3}$ in pyridine as an activator yielded $\mathbf{5 a}$ in $50 \%$ yield. However, we recognized multiple issues with the 2 -OTBS protection based on prior literature, including instability in ammonia solutions, ${ }^{\mathbf{1 5}}$ chain cleavage, ${ }^{16}$ silyl migration to the $3^{\prime}$-alcohol, ${ }^{17}$ and longer coupling times during oligonucleotide synthesis due to steric bulk. ${ }^{18}$ Hence, we switched to trimethylsilyl-ethoxymethyl (SEM) as a $2^{\prime}$-alcohol protecting group, which resulted in a higher yield (5b, 74\%). Next, the $3^{\prime}, 5^{\prime}$-O-di(tert-butyl)silyl group was selectively deprotected using Olah's reagent to afford 6 in $82 \%$ yield. Finally, 1 was prepared in $40 \%$ yield over two steps by protecting the $5^{\prime}$-OH with 4,4'-dimethoxytrityl chloride (DMTCl), followed by the reaction with 2-cyanoethyl $N, N$-diisopropylchlorophosphoramidite. Taken together, GS-441524 phosphoramidite 1 was synthesized in 6 linear steps with an overall yield of $14 \%$ (Scheme 2). A notable advantage of our work in comparison to the published GS-441524 phosphoramidite synthesis is the lack of a requirement for isomerization of a $3^{\prime}$ OTBS group to install the requisite 2 -OTBS protecting group, which occurs in modest yield, and concomitant separation of $2^{\prime}$ OTBS and $3^{\prime}$-OTBS isomers. ${ }^{5}$

We further investigated approaches to improve the yield of the first two steps of the synthesis of 1. Accordingly, we found that protecting the exocyclic amine of GS-441524 with $\mathrm{N}, \mathrm{N}$ dimethylformamide dimethyl acetal in DMF in the first step

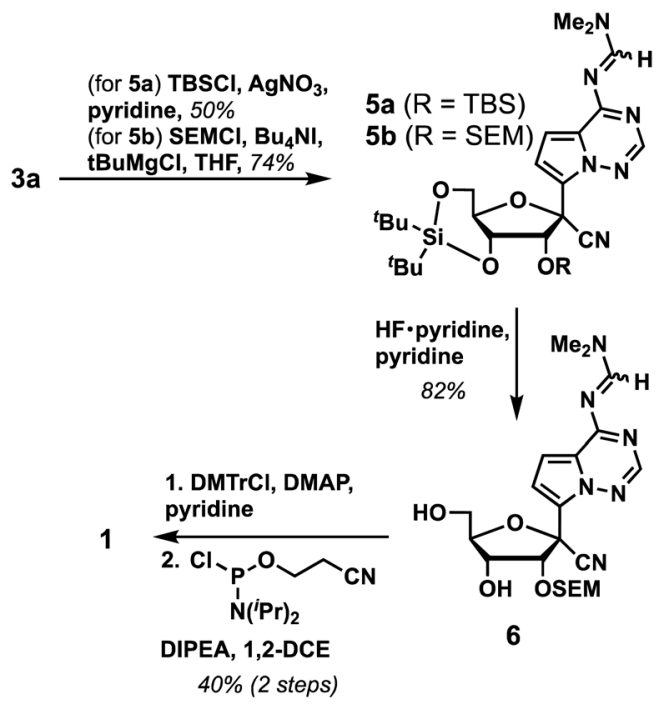

Scheme 2 Synthesis of GS-441524 phosphoramidite 1. 


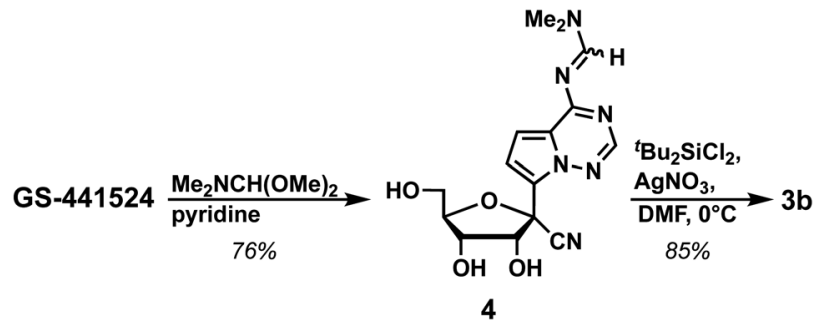

Scheme 3 Synthesis of $3 b$

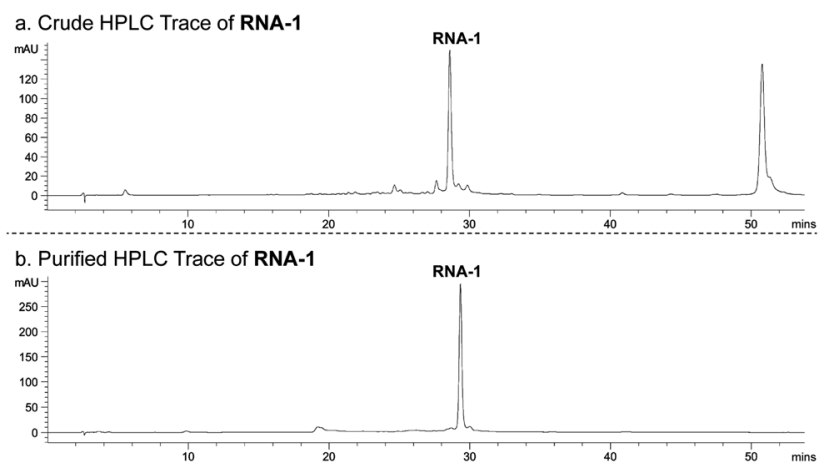

Fig. 2 HPLC chromatogram of (a) crude RNA-1 and (b) HPLC-purified RNA-1 (monitored at $260 \mathrm{~nm}$ ).

resulted in formation of 4 in $66 \%$ yield. Changing the solvent from DMF to pyridine resulted in a higher yield (76\%; Scheme $3)$. Next, the $3^{\prime}$ - and $5^{\prime}$-alcohols were protected using di(tertbutyl)chlorosilane in high yield (85\%, see ESI: $\dagger$ 3b). To our delight, switching the protection sequence improved the overall yield (65\% for two steps) compared to the previous strategy (Scheme 1 and Table 1, 56\% for two steps), as well as yielded single diastereomer $\mathbf{3 b}$, which simplified chromatographic separation. This modified strategy can be utilized for the synthesis of GS-441524 phosphoramidite 1 as shown in Scheme 2.

With phosphoramidite 1 in-hand, we utilized standard RNA synthesis methods to prepare 5'-CCGGGCGGCR-3' (RNA-1), where $\mathrm{R}$ is GS-441524. RNA-1 was synthesized in reasonable yield (135 nmol from a $1000 \mathrm{nmol}$-scale synthesis) and high purity (91\% following HPLC purification; Fig. 2).

In conclusion, we have developed an efficient synthesis of a GS-441524 phosphoramidite that requires six linear steps and results in an overall yield of 14\% starting from the GS-441524 nucleoside. GS-441524-containing phosphoramidite 1 was successfully used in automated solid-phase RNA synthesis to demonstrate the utility of our novel phosphoramidite. Phosphoramidite 1 thus serves as a useful new reagent for preparing RNA containing the promising antiviral drug remdesivir.

\section{Author contributions}

RM and DAH designed the phosphoramidite synthesis; RM and DJR synthesized compounds. SAK synthesized the RNA. RM,
SAK and DAH wrote the manuscript, and all authors agree to its submission.

\section{Conflicts of interest}

The authors declare no conflicts of interest.

\section{Acknowledgements}

We gratefully acknowledge the NIH (P01-CA234228) and the University of Minnesota for financial support. Mass spectrometry was performed at the University of Minnesota Masonic Cancer Center Analytical Biochemistry Core Facility, which is supported by the NIH (P30-CA77598).

\section{Notes and references}

1 (a) A. Cho, O. L. Saunders, T. Butler, L. Zhang, J. Xu, J. E. Vela, J. Y. Feng, A. S. Ray and C. U. Kim, Bioorg. Med. Chem. Lett., 2012, 22, 2705; (b) S. Metobo, J. Xu, O. L. Saunders, T. Butler, E. Aktoudianakis, A. Cho and C. U. Kim, Tetrahedron Lett., 2012, 53, 484.

2 (a) J. H. Beigel, K. M. Tomashek, L. E. Dodd, L. A. K. Mehta, B. S. Zingman, A. C. Kalil, E. Hohmann, H. Y. Chu, A. Luetkemeyer, S. Kline, D. Lopez de Castilla, R. W. Finberg, K. Dierberg, V. Tapson, L. Hsieh, T. F. Patterson, R. Paredes, D. A. Sweeney, W. R. Short, G. Touloumi, D. C. Lye, N. Ohmagari, M. D. Oh, G. M. Ruiz-Palacios, T. Benfield, G. Fätkenheuer, M. G. Kortepeter, R. L. Atmar, C. B. Creech, J. Lundgren, A. G. Babiker, S. Pett, J. D. Neaton, T. H. Burgess, T. Bonnett, M. Green, M. Makowski, A. Osinusi, S. Nayak and H. C. Lane, N. Engl. J. Med., 2020, 383, 1813; (b) R. T. Eastman, J. S. Roth, K. R. Brimacombe, A. Simeonov, M. Shen, S. Patnaik and M. D. Hall, ACS Cent. Sci., 2020, 6, 672.

3 (a) D. Siegel, H. C. Hui, E. Doerffler, M. O. Clarke, K. Chun, L. Zhang, S. Neville, E. Carra, W. Lew, B. Ross, Q. Wang, L. Wolfe, R. Jordan, V. Soloveva, J. Knox, J. Perry, M. Perron, K. M. Stray, O. Barauskas, J. Y. Feng, Y. Xu, G. Lee, A. L. Rheingold, A. S. Ray, R. Bannister, R. Strickley, S. Swaminathan, W. A. Lee, S. Bavari, T. Cihlar, M. K. Lo, T. K. Warren and R. L. Mackman, J. Med. Chem., 2017, 60, 1648; (b) Y. Li, L. Cao, G. Li, F. Cong, Y. Li, J. Sun, Y. Luo, G. Chen, G. Li, P. Wang, F. Xing, Y. Ji, J. Zhao, Y. Zhang, D. Guo and X. Zhang, J. Med. Chem., 2021, DOI: 10.1021/ acs.jmedchem.0c01929.

4 (a) W. Yin, C. Mao, X. Luan, D.-D. Shen, Q. Shen, H. Su, X. Wang, F. Zhou, W. Zhao, M. Gao, S. Chang, Y.-C. Xie, G. Tian, H.-W. Jiang, S.-C. Tao, J. Shen, Y. Jiang, H. Jiang, Y. Xu, S. Zhang, Y. Zhang and H. E. Xu, Science, 2020, 368, 1499; (b) C. J. Gordon, E. P. Tchesnokov, E. Woolner, J. K. Perry, J. Y. Feng, D. P. Porter and M. Götte, J. Biol. Chem., 2020, 295, 6785; (c) C. J. Gordon, E. P. Tchesnokov, J. Y. Feng, D. P. Porter and M. Götte, J. Biol. Chem., 2020, 295, 4773. 
5 G. Kokic, H. S. Hillen, D. Tegunov, C. Dienemann, F. Seitz, J. Schmitzova, L. Farnung, A. Siewert, C. Höbartner and P. Cramer, Nat. Commun., 2021, 12, 279.

6 (a) G. S. Ti, B. L. Gaffney and R. A. Jones, J. Am. Chem. Soc., 1982, 104, 1316; (b) W. L. Sung and S. A. Narang, Can. J. Chem., 1982, 60, 111; (c) X.-F. Zhu, W. J. Howard and A. I. Scott, Synth. Commun., 2003, 33, 1233.

7 (a) K. Furusawa, K. Ueno and T. Katsura, Chem. Lett., 1990, 19, 97; (b) B. M. Trost and C. G. Caldwell, Tetrahedron Lett., 1981, 22, 4999.

8 K. Furusawa, Chem. Lett., 1989, 18, 509.

9 M. Sekine, S. Iimura and K. Furusawa, J. Org. Chem., 1993, 58, 3204.

10 (a) M. Pfister, H. Schirmeister, M. Mohr, S. Farkas, K. P. Stengele, T. Reiner, M. Dunkel, S. Gokhale, R. Charubala and W. Pfleiderer, Helv. Chim. Acta, 1995, 78, 1705; (b) S. Matysiak and W. Pfleiderer, Helv. Chim. Acta, 2001, 84, 1066.

11 (a) C. B. Reese, R. Saffhill and J. E. Sulston, J. Am. Chem. Soc., 1967, 89, 3366; (b) A. Sandstroem, M. Kwiatkowski and J. Chattopadhyaya, Acta Chem. Scand., Ser. B, 1985, 39, 273; (c) A. Sandstroem, M. Kwiatkowski and J. Chattopadhyaya, Nucleosides Nucleotides, 1985, 4, 177; (d) W. Lloyd, C. B. Reese, Q. Song, A. M. Vandersteen, C. Vistina and P. Z. Zhang, J. Chem. Soc., Perkin Trans. 1, 2000, 165.

12 (a) K. K. Ogilvie, K. L. Sadana, E. A. Thompson, M. A. Quilliam and J. B. Westmore, Tetrahedron Lett., 1974,
33, 2861; (b) K. K. Ogilvie, N. Theriault and K. L. Sadana, J. Am. Chem. Soc., 1977, 99, 7741; (c) N. Usman, K. K. Ogilvie, M. Y. Jiang and R. J. Cedergren, J. Am. Chem. Soc., 1987, 109, 7845; (d) T. Umemoto and T. Wada, Tetrahedron Lett., 2004, 45, 9529; (e) S. Pitsch, P. A. Weiss, L. Jenny, A. Stutz and X. Wu, Helv. Chim. Acta, 2001, 84, 3773; $(f)$ T. Ohgi, Y. Masutomi, K. Ishiyama, H. Kitagawa, Y. Shiba and J. Yano, Org. Lett., 2005, 7, 3477; (g) C. Zhou, D. Honcharenko and J. Chattopadhyaya, Org. Biomol. Chem., 2007, 5, 333; (h) T. Wada, M. Tobe, T. Nagayama, K. Furusawa and M. Sekine, Tetrahedron Lett., 1995, 36, 1683.

13 A. Semenyuk, A. Foldesi, T. Johansson, C. Estmer-Nilsson, P. Blomgren, M. Brannvall, L. A. Kirsebom and M. Kwiatkowski, J. Am. Chem. Soc., 2006, 128, 12356.

14 (a) S. G. Chaulk and A. M. MacMillan, Nucleic Acids Res., 1998, 26, 3173; (b) M. E. Schwartz, R. R. Breaker, G. T. Asteriadis, J. S. de Bear and G. R. Gough, Bioorg. Med. Chem. Lett., 1992, 2, 1019.

15 J. Stawinski, R. Strömberg, M. Thelin and E. Westman, Nucleic Acids Res., 1988, 16, 9285.

16 T. Wu, K. K. Ogilvie and R. T. Pon, Nucleic Acids Res., 1989, 17, 3501.

17 S. S. Jones and C. B. Reese, J. Chem. Soc., Perkin Trans. 1, 1979, 2762.

18 S. A. Scaringe, C. Francklyn and N. Usman, Nucleic Acids Res., 1990, 18, 5433. 